\title{
Discriminant Analysis of Factors Affecting Telecoms Customer Churn
}

\author{
Benjamin Oghojafor \\ Department of Business Administration, \\ University of Lagos, Akoka, Nigeria \\ Tel: +234-803-300-0522Ｅ-mail: akpoyomareo@yahoo.co.uk \\ Godson Mesike (Corresponding author) \\ Department of Actuarial Science and Insurance, \\ University of Lagos, Akoka, Nigeria \\ Tel: +234-803-699-7235Ｅ-mail: mesikegodson@yahoo.co.uk \\ Rasaki Bakarea \\ Department of Business Administration, \\ University of Lagos, Akoka, Nigeria \\ Tel:+234-802-851-1139_E-mail: adebak2@yahoo.com \\ Charles Omoera \\ Department of Business Administration, \\ University of Lagos, Akoka, Nigeria \\ Tel: +234-802-389-8721Ｅ-mail: charlesmotohan@yahoo.com \\ Ismaila Adeleke \\ Department of Actuarial Science and Insurance, \\ University of Lagos, Akoka, Nigeria \\ Tel: +234-803-564-8121_E-mail: adeleke22000@yahoo.ca
}

Received: October 25, 2011

Accepted: January 5, 2012 Published: March 15, 2012

doi:10.5430/ijba.v3n2p59

URL: http://dx.doi.org/10.5430/ijba.v3n2p59

\begin{abstract}
A major challenge facing telecoms business providers in Nigeria today is the continuous growing competition and customers' expectation of service quality and as such customers are able to choose among multiple service providers based on the level of satisfaction, affordability, and service quality of service providers. Customer demand and competition are forcing firms to cut loose from the traditional customer satisfaction paradigm, to adopt proactive strategies which will assist them to take the lead in the market-place. This study aims at identifying factors that discriminate among subscribers exhibiting willingness to drop their current service provider and those willing to stay. The study also examines the effect of socio-economic and demographic factors associated with the identified discriminants. The major factors identified are high call rate, poor service facilities, off-beam advertisement medium, availability of superior service provider and unattractive service plan.
\end{abstract}

Keywords: Telecommunication, Churn Rate, Discriminant, Service Provider, Customers Satisfaction 


\section{Introduction}

The Nigerian telecommunication industry has experienced phenomenal growth in its subscribers' base making it a highly competitive sector. And in this strongly competitive and liberalized telecommunication industry, customers are able to choose among multiple service providers based on the level of satisfaction, affordability, and service quality of service providers. A major challenge facing telecoms business providers in Nigeria today is the continuous growing competition and customers' expectation of service quality. Customer demand and competition are forcing firms to cut loose from the traditional customer satisfaction paradigm, to adopt proactive strategies which will assist them to take the lead in the market-place. Though, the basis of service quality as a competitive edge in gaining market leadership through customers' satisfaction has been well recognized both in academic research and by leading service organizations (Kandampully, 1998; Kotler and Keller, 2006), however, it has become increasingly important for organizations to unearth ways, not only to reach the zenith, but to sustain that leadership in an ever increasing competitive market-place. Consequently, in protecting its long-term interest, service organizations are seeking ways to foster and maintain continuous relationship with their customers. Most telecommunications service providers are deploying retention strategies; harmonized in programs and processes to keep customers by providing them with tailored products and services. Subsequently, many companies have started to include churn reduction as one of their business goals. All service providers lose customers to some other competing companies due to various reasons but it should be clear that the survival of any business is dependent on its capability to maintain and retain customers. This is predominantly factual for the telecom service providers, hence the need for churn reduction.

However, two critical issues facing telecom service providers as the telecom market grows are market share and competitive advantage. Obviously, the prospects associated with market expansion will certainly result in a greater number of providers, thus, gaining or maintaining market share through a means that provides an unparalleled competitive advantage will strongly figure into a provider's business plan (see Chen and Ching, 2007). Though as noted by Chen and Ching (2007), technology can provide a competitive advantage for service provider, however this advantage is only provisional as it disappears once the technology becomes readily available to everyone. Therefore a better approach lies in adopting technology to leverage a customer-centric approach that focuses the business on retaining existing customer and seeking their loyalty (see Chen and Ching, 2007). Keeping in view the fact that cost of obtaining new customer is five times higher than maintaining an existing customer and that service providers spent huge amount on advertisement to gain a customer (Khan, Jamwal and Sepehri, 2010), service providers need not to lose their existing customers and hence must fight customer churn.

In particular, Khan et al (2010) identified two basic approaches to fight customer churn. The first is untargeted approach which relies basically on superior product and mass advertising to increase brand loyalty and customers' retention. The second which could either be reactive or proactive is targeted approach which relies on identifying customers who are likely to churn, and then either provide them with a direct incentive or customize service plan to make them stay. Adopting a reactive approach, a company waits until customers informs them of their intention to cancel their (service) relationship before offering the customer incentives, for example a rebate, to stay while in adopting a proactive approach, a company tries to identify customers who are likely to churn at some later date in advance. The company then targets these customers with special programmes or incentives to keep the customers from churning. Targeted proactive programs have potential advantages of having lower incentive costs and because customers are not trained to negotiate for better deals under the threat of churning. However these systems could be very wasteful if churn predictions are erroneous, because the companies would be wasting incentive money on customers who would have stayed anyway. That is why the customers churn prediction processes needed to be as accurate as possible (Burez and Van den Poel, 2006).

Hughes (2008) enumerated various measures of reducing customer churn. Some of which are offering better products, better delivery methods, lowering prices, building satisfactory customer relationships, better marketing and, above all, successful customer communications.

Studies have shown that good service quality leads to the retention of existing customers and the attraction of new ones (See Kotler and Keller, 2006), just as (Reichheld and Sasser, 1990; Cronin et al., 2000; Kang and James, 2004; Yoon and Suh, 2004) reiterated that reduction in costs, enhanced corporate image and positive word-of-mouth recommendation also enhance customer loyalty. Omotayo and Joachim (2008) in their study of relationship between customer service and customer retention in telecoms industry identified choices, conveniences, prices, and income as key factors to be considered if subscribers must be retained. They noted that customer service enhance customer retention. Khan, Jamwal and Sepehri (2010) agreed with previous studies of (Bitner and Hubbert, 1994; Cronin and Taylor, 1992; Zeithaml, Berry and Parasuraman, 1996; Lee and Murphy 2008) that Service quality, consumers' appraisal of overall quality or service excellence, may influence customers' decisions to remain with or churn current service providers. They emphasized that 
favourable service quality would increase loyalty, retention and reduce churn. Al-Rousan, Ramzi and Mohamed (2010) in their study concluded that service quality significantly influenced customers' loyalty. For further studies on customers retention see Swan and Comb (1976), Zeithaml (1987), Gagliano, and Hathcote (1994), Fredericks and Salter (1995), Zeithaml, Berry, and Parasuraman (1996), Yi and Alison(2001), Wong and Sohal (2003). This study attempts identifying factors that discriminate among subscribers exhibiting willingness to churn their current service provider and those willing to stay. The study also examines the effect of socio-economic and demographic factors associated with the identified discriminants.

\section{Data and Methods}

\subsection{Data}

We employed a sample survey in this study. The survey was targeted at major urban areas in Lagos State where the mainstream of the population are located. The survey which was conducted between January and April 2011 involved the collection of information from individual subscribers on their satisfaction of telecommunication network providers. The main instrument of the survey was a structured questionnaire.

A two stage sampling technique was used in the study, the first step is to select a sample of units, often called primary units, and the second is to select a sample of subunits from each chosen primary unit. It is uneconomical to measure all the units in a selected sample if subunits within the selected units give similar results. The major advantage of this sampling method is that it is more flexible than one-stage sampling as it accords us the possibility to take smaller units that produce high efficiency (Cochran, 1977).

\subsection{Population Study and Sample Size}

Lagos has the most heterogeneous concentrations of people in the country with many linguistic and cultural groups living together. A random sample of all the local government areas were selected for our study and 800 randomly selected consumers were examined for customer satisfaction on telecommunication network provider. For the purpose of this study, data were collected from individual subscribers. The questionnaire captured information on demographic, socio-economic data of the respondent such as the income of the respondents, their age, educational level and employment status in addition to effectiveness and willingness to change service provider. Our instruments also attempt to capture affordability, social networking, cultural effect and satisfaction of service network provider.

\section{Methods}

Descriptive statistics was used to explore the data before applying multivariate analysis. Multivariate analysis comprises a set of techniques dedicated to the analysis of data sets with more than one variable (Abdi, 2003). We applied discriminant analysis to examine the effect of socio-economic factors that discriminate between those that are willing to stay with a service provider and those willing to buy and to evaluate customer churn for telecom service provider. Discriminant analysis is used to assess the adequacy of classification, given the group memberships of the objects under study or to assign objects to one of a number of (known) groups of objects.

\section{Results and Discussion}

Table 1 provides the descriptive statistics of telecom subscribers' churn rate. The result shows the average annual churn rate of subscribers to be $26 \%$. Though it could be low as $2 \%$ but could escalate as high as $48 \%$. This implies that the rate at which customers churn their service providers is high and therefore service providers should develop proactive retentive strategy geared towards maintaining customers and reduced churn in their subscribers base.

Table 2 shows the characteristics of telecom subscribers, the result shows that the most preferred mode of advertising by subscribers is Radio with $31.5 \%$, an average of $51.1 \%$ of telecom subscribers have two mobile connections, specifically, $71.2 \%$ of the subscribers prefer prepaid service. The result also showed that availability of network service, at $46.9 \%$, is a major drive for subscribers staying with a service provider.

Table 3 presents the results of the discriminant analysis of telecoms subscribers. This analysis developed a set of discriminating functions which helps in predicting the willingness of subscribers to churn their current service provider. The value of the Wilk's lambda at 0.748 and the p-value (0.000) shows that the canonical discriminant function has a greater discriminatory ability of the function and was credible and effective. Using the maximum likelihood stepwise procedure, with 12 discriminant parameters, the results shows that type of service plan, service facilities, call expenses, number of mobile connections, and advertising medium were the most discriminant parameters for subscribers churning service providers, with correct assignations. Thus, the results suggested that these five discriminant parameters were needed to account for most of the expected churn variation for churning service providers by subscribers. 
Table 4 shows the classification function coefficients of the five identified most discriminants which discriminate among subscribers exhibiting willingness to churn when put in order of importance, are call expenses, service facilities , advertising medium, number of mobile connection and type of service plan respectively.

Table 5 provides a cross tabulation of the discriminants with subscriber's willingness to churn service providers. The p-value shows a strong statistical significance of these identified discriminants on subscribers' willingness to churn service providers. This means that call expenses, advertising medium, the number of mobile Connections a subscribers has, type of service plan used and the service facilities available with a provider are germane to subscribers' decision to churn. Interestingly, of the subscribers whose call rate ranges between N5,000 and N20,000, about $98 \%$ are ready to churn service providers. This reveals that such high value subscribers should be targeted for proactive retention approach.

The result further reveals that subscribers with more than three network connections have higher tendency to churn than those with lesser number of connections whereas of the subscribers attracted by providers' service facilities, readiness to churn are predominantly high with those in call rate and network availability.

Table 6 shows a cross-tabulation of some socio-economic and demographic characteristics with the identified discriminants. The result indicates a statistically significance relationship of these identified discriminants with the socio-economic and demographic characteristics. Though, while all the socio-economic and demographic characteristics considered are significant with the identified discriminant factors, it is interesting to note that number of mobile connection a subscriber has, type of service plan used and service facilities available are not significantly influenced by the gender of the subscribers. This means that service providers should direct their retention marketing strategy to subscribers irrespective of their gender. The above findings suggest that since the discriminant factors cut across various socio-economic and demographic characteristics, service providers must ensure that proactive measures are taken to make subscribers' retention feasible.

\section{Conclusion}

The phenomenal growth experienced in Nigeria's telecom industry brought to the fore the emergence of consumer-driven tactics and strategies by service providers to ensure that they attract new customers and retain the existing customers. In this study factors that discriminate among subscribers exhibiting willingness to churn their current service providers were identified using discriminant analysis. Unattractive service plan, poor service facilities, high call rates, availability of superior alternative service provider, and off-beam advertisement medium were identified as pivot factors which significantly discriminate among telecoms subscribers willing to churn and those exhibiting loyalty. In order of importance, high call rates more often than not tend to induce subscribers to churn followed by poor service facilities, advertising medium, number of mobile connection and alternative availability of superior provider respectively. The model in figure 2 depicts this assertion.

To remain successfully competitive in value and price-conscious environment, it is imperative for telecoms service providers to improve performance on each factor as a strategies with which churn reduction can be actualized.

\section{References}

Abdi, H. (2003). Partial Least Square Regression, Encyclopedia for Research Methods for the Social Sciences, Sage, CA.

Abdi, H. (2007). Discriminant Correspondence Analysis. Encyclopedia of Measurement \& Statistics. Thous\& Oaks (CA): Sage. pp. 270-275.

Al-Rousan, M. R. \& Badaruddin, M. (2010). “Customer Loyalty \& the Impacts of Service Quality: The Case of Five Star Hotels in Jordan", International Journal of Human \& Social Sciences 5:13

Burez, J. \& Van den Poel, D. (2006). "CRM at a pay-TV company: Using analytical models to reduce customer attrition by targeted marketing for subscription services.”, Expert Systems with Applications 101: 512-524.

Cochran, W. G. (1977). Sampling techniques, (3rd ed.). New York: John Wiley \& sons.

Chen, J. \& Ching, R. (2007). The Effects of Mobile Customer Relationship Management on Customer Loyalty: Br\& Image Does Matter Proceedings of the 40th Hawaii International Conference on System Sciences

Fredericks, J. O. \& Salter, J. M. II (1995). “Beyond customer satisfaction”. Management Review, 84, pp. 29- 32

Gagliano, K. B. \& Hathcote, J. (1994). "Customer Expectations \& Perceptions of Service Quality in Apparel Retailing". Journal of Services Marketing, 1(8), 60-69. http://dx.doi.org/10.1108/08876049410053311

Hughes, A. M. (2008). Churn reduction in the telecom industry, Database Marketing Institute Limited 
K\&ampully, J. (1998). "Service quality to service loyalty: A relationship which goes beyond customer services", Total Quality Management, Vol. 9, no. 6, 1998, 431- 443. http://dx.doi.org/10.1080/0954412988370

K\&ampully, J. (1997). "Firms should give loyalty before they can expect it from customers", Managing Service Marketing, April, 40, pp. 25 - 33.

Khan, A.A; Jamwal, S. \& Sepehri, M.M. (2010). "Applying Data Mining to Customer Churn Prediction in an Internet Service Provider". International Journal of Computer Applications Volume 9- No.7

Kotler, P. \& Keller, K. (2006). Marketing Management (12 ${ }^{\text {th }}$ ed.). Upper Saddle River, New jersey Pearson International Edition

Lee, R. \& Murphy, J. (2008). The Moderating Influence of Enjoyment on Customer Loyalty, Australasian Marketing $\begin{array}{llllll}\text { Journal } & 16 & (2), & \text { NCC } & \text { (2011). } & \text { [Online] }\end{array}$ http://www.ncc.gov.ng/industrystatistics/studies/pyramid-impactofmobileservicesinNigeria.pdf accessed on August 1st, 2011.

Omotayo, O. \& Joachim, A. (2008). "Customer service in the retention of mobile phone users in Nigeria", African Journal of Business Management Vol.2 (2), pp. 026-031

Parasuraman, A., Berry, L. L \& Zeithaml, V A. (1991). "Underst\&ing Customer Expectations of Service". Sloan Management Review, 32(3), 39-48.

Swan, J. E. \& Comb, L. J. (1976). "Product performance \& consumer satisfaction: a new concept". Journal of Quality, 7(2), pp. $92-94$

Wong, A. \& Sohal, A. (2003). "Service quality \& customer loyalty; perspectives on two levels of retail relationships". Journal of Services Marketing, 17(5), 495 - 513. http://dx.doi.org/10.1108/08876040310486285

Yi, T. Y., \& Alison, D. (2001). "The contribution of emotional satisfaction to consumer Loyalty”. International journal of service industry management, 12 (234-250). http://dx.doi.org/10.1108/09564230110393239

Zeithaml, V. A. (1987). Defining \& Relating Price, Perceived Quality \& Perceived Value, Report No. 87-101 (Cambridge, MA, Marketing Science Institute).

Zeithaml, V. A., Berry, L. L. \& Parasuraman, A. (1996). The behavioral consequences of service quality: Journal of Marketing, 60, 31-46. http://dx.doi.org/10.2307/1251929

Table 1. Descriptive statistics of telecom subscribers' annual churn rate

\begin{tabular}{|c|c|}
\hline & Annual Churn rate \\
\hline & \\
\hline Mean & 26 \\
\hline Standard Error & 0.05 \\
\hline Median & 27 \\
\hline Standard Deviation & 0.16 \\
\hline Sample Variance & 0.03 \\
\hline Kurtosis & -1.17 \\
\hline Skewness & -0.03 \\
\hline Range & 46 \\
\hline Minimum & 2 \\
\hline Maximum & 48 \\
\hline
\end{tabular}

Source: NCC, 2011 
Table 2. Characteristics of telecoms subscribers

\begin{tabular}{|c|c|}
\hline Variable & Percentage \\
\hline \multicolumn{2}{|c|}{ Which advertising media puts more impact on your buying decision? } \\
\hline TV & 16.4 \\
\hline Magazine & 19.9 \\
\hline Radio & 31.5 \\
\hline Internet & 27.3 \\
\hline Newspaper & .5 \\
\hline Others & 4.5 \\
\hline \multicolumn{2}{|c|}{ How many mobile connections do you have? } \\
\hline One & 24.4 \\
\hline Two & 51.1 \\
\hline Three & 8.7 \\
\hline More than three & 15.7 \\
\hline \multicolumn{2}{|c|}{ Which service are you currently using? } \\
\hline Prepaid & 71.2 \\
\hline Post paid & 28.8 \\
\hline \multicolumn{2}{|c|}{ Which facility attracts you the most? } \\
\hline Coverage & 10.5 \\
\hline Call charges & 42.6 \\
\hline Availability & 46.9 \\
\hline \multicolumn{2}{|c|}{ Would you like to change your current service provider in the future? } \\
\hline Yes & 31.3 \\
\hline No & 68.7 \\
\hline
\end{tabular}

Source: survey 2011

Table 3. Discriminant classification function coefficients

\begin{tabular}{|c|c|}
\hline & Classification function coefficients \\
\hline Gender & .024 \\
\hline Marital status & -.089 \\
\hline Age & -.039 \\
\hline Place of residence & .091 \\
\hline Occupation (category of respondent) & .047 \\
\hline Income & .056 \\
\hline Call Expenses & .910 \\
\hline Job status & .051 \\
\hline Educational level & -.102 \\
\hline Advertising medium & -.457 \\
\hline No of mobile connections & .415 \\
\hline Type of service plan & .292 \\
\hline Service facility & .770 \\
\hline
\end{tabular}

p-value $=0.000$, Wilks' Lambda $=0.748$ 
Table 4. Discriminant classification function coefficients

\begin{tabular}{|c|c|}
\hline & Classification function coeffcients \\
\hline Call Expenses & .884 \\
\hline Advertising medium & -.527 \\
\hline No of mobile connections & .391 \\
\hline Type of service plan & .378 \\
\hline Service facility & .842 \\
\hline
\end{tabular}

p-value $=0.000$, Wilks' Lambda $=0.17$

Table 5. Effect of identified discriminants on customers churn

\begin{tabular}{|c|c|c|c|c|}
\hline \multirow[t]{2}{*}{ Factors } & \multicolumn{2}{|c|}{ Willingness to Churn } & \multirow[t]{2}{*}{$X^{2}$} & \multirow[t]{2}{*}{ P-Value } \\
\hline & Yes & No & & \\
\hline Call Expenses & & & 587.168 & 0.000 \\
\hline Below 1000 & 25.3 & 74.7 & & \\
\hline $1000-5000$ & 21.9 & 78.1 & & \\
\hline $5000-20000$ & 49.0 & 51.1 & & \\
\hline Advertising Medium & & & 633.011 & 0.000 \\
\hline Television & 46.2 & 53.8 & & \\
\hline Magazine & 80 & 20 & & \\
\hline Radio & 1.6 & 98.4 & & \\
\hline Internet & 24.5 & 75.5 & & \\
\hline Others & 94.2 & 5.8 & & \\
\hline No of Mobile Connection & & & 60.615 & 0.000 \\
\hline One & 34.2 & 65.8 & & \\
\hline Two & 24.9 & 75.1 & & \\
\hline Three & 30.7 & 69.3 & & \\
\hline More than three & 47.6 & 52.4 & & \\
\hline Type of Service Plan & & & 30.825 & 0.000 \\
\hline Prepaid & 27.4 & 72.6 & & \\
\hline Postpaid & 40.1 & 59.9 & & \\
\hline Which facility attract you the most & & & 103.512 & 0.000 \\
\hline Coverage & 2.4 & 97.6 & & \\
\hline Call charges & 30.4 & 69.6 & & \\
\hline Availability & 38.3 & 61.7 & & \\
\hline
\end{tabular}

Source: survey 2011 
Table 6. Effect socio-economic and demographic characteristics of subscribers on identified discriminants

\begin{tabular}{|c|c|c|c|c|c|}
\hline & \multicolumn{5}{|c|}{ Discriminants } \\
\hline $\begin{array}{c}\text { Socio-economic and } \\
\text { Demographic variables }\end{array}$ & $\begin{array}{c}\text { Call } \\
\text { Expenses }\end{array}$ & $\begin{array}{c}\text { Advertising } \\
\text { Medium }\end{array}$ & $\begin{array}{c}\text { No of Mobile } \\
\text { Connection }\end{array}$ & $\begin{array}{c}\text { Type of } \\
\text { Service Plan }\end{array}$ & $\begin{array}{c}\text { Service } \\
\text { facility }\end{array}$ \\
\hline Marital Status & $15.937^{* *}$ & $69.025^{* *}$ & $13.774^{* *}$ & $1.320^{* *}$ & $7.629^{*}$ \\
\hline Age & $50.176^{* *}$ & $2193.216^{* *}$ & $98.725^{* *}$ & $22.140^{* *}$ & $21.013^{* *}$ \\
\hline Occupational Status & $640.397^{* *}$ & $838.126^{* *}$ & $404.079^{* *}$ & $159.579^{* *}$ & $294.937^{* *}$ \\
\hline Income & $293.681^{* *}$ & $2332.092^{* *}$ & $869.219^{* *}$ & $161.164^{* *}$ & $443.905^{* *}$ \\
\hline Place of Residence & $700.865^{* *}$ & $1482.705^{* *}$ & $792.682^{* *}$ & $160.727^{* *}$ & $325.182^{* *}$ \\
\hline Employment Description & $275.349^{* *}$ & $950.946^{* *}$ & $780.496^{* *}$ & $182.377^{* *}$ & $258.855^{* *}$ \\
\hline Educational Level & $1176.167^{* *}$ & $2369.904^{* *}$ & $1042.784^{* *}$ & $194.121^{* *}$ & $565.947^{* *}$ \\
\hline Gender & $15.178^{* *}$ & $22.279^{* *}$ & 3.042 & 2.293 & 2.500 \\
\hline
\end{tabular}

$* \mathrm{P} \leq 0.05, * * \mathrm{P} \leq 0.01$.

$60.00 \%$

$50.00 \%$

$40.00 \%$

$30.00 \%$

$20.00 \%$

$10.00 \%$

$0.00 \%$

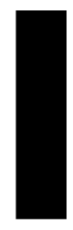

2001

2003

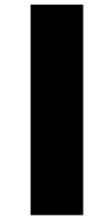

2004

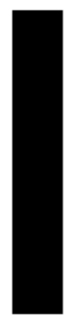

2005
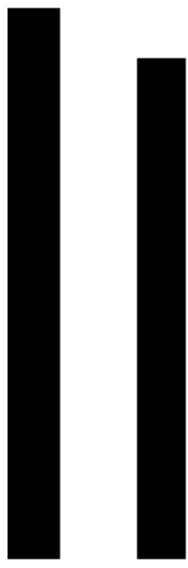

2006

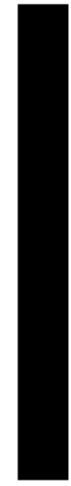

2009

Figure 1. Annual churn rate of telecom subscribers in Nigeria (2001-2009)

Source: NCC 2011 


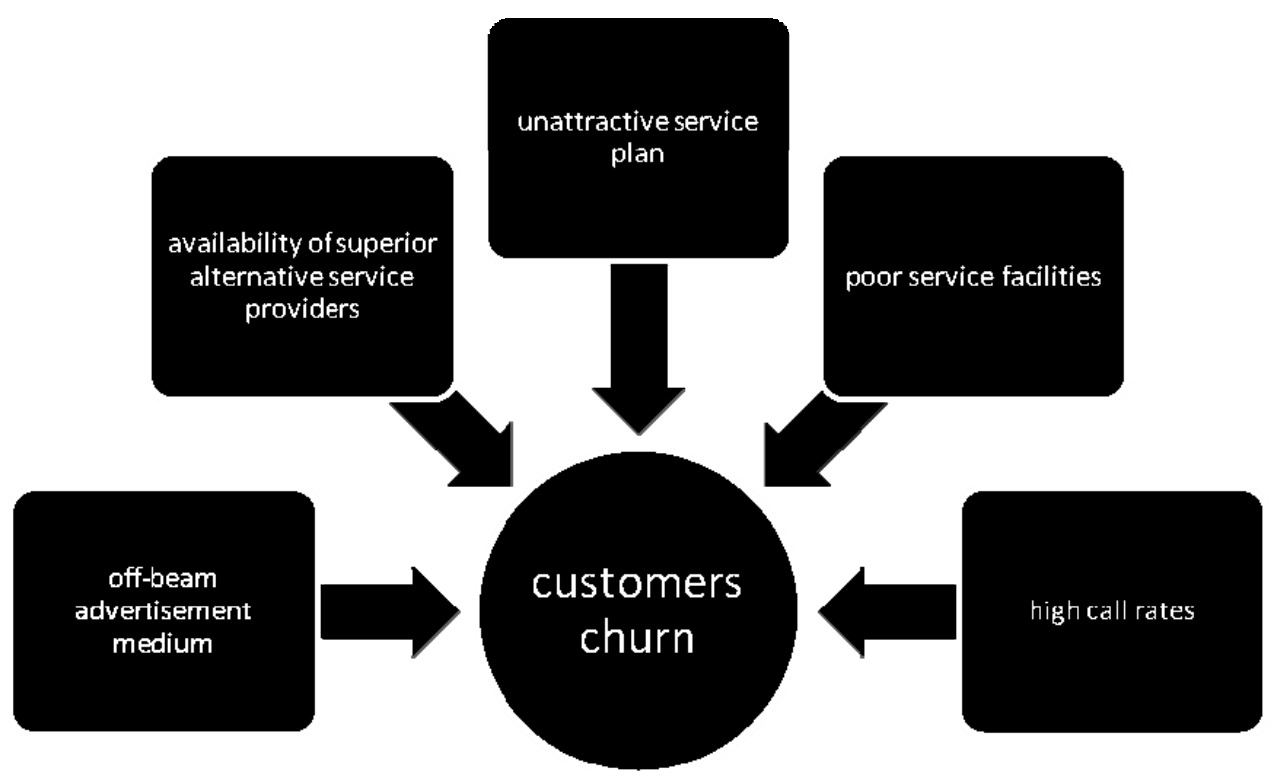

Figure 2. Customer Churn Model

Source: survey results, 2011 